\title{
Volatile and Nonvolatile Flavor Chemical Evaluation of USDA Orange-Mandarin Hybrids for Comparison to Sweet Orange and Mandarin Fruit
}

\author{
Jinhe Bai', Elizabeth Baldwin, Jack Hearn, Randy Driggers, and Ed Stover \\ U.S. Department of Agriculture, Agricultural Research Service, U.S. Horticultural Research \\ Laboratory, 2001 South Rock Road, Fort Pierce, FL 34945
}

\begin{abstract}
Additional INDEX words. citrus, aroma, sesquiterpene, interaction of flavor compounds, sugar, acid
Abstract. Three citrus hybrids, containing 50\% to $75 \%$ sweet orange (Citrus sinensis) genome in their pedigrees and similar to sweet orange in fruit size, color, and taste, were tested for their potential to be classified as new "sweet orange" cultivars. 'Hamlin', 'Midsweet', and three other early to midseason sweet oranges, along with 'Dancy' tangerine (Citrus reticulata), a typical mandarin, were used for comparison. Fruit were picked on 23 Jan. 2014,30 Dec. 2014, and 27 Jan. 2015. A total of 114 volatiles were detected and separated into seven groups by detection frequency: three groups with 43 volatile components did not show differences and thus contributed little information for classification of sweet orange vs. mandarin, and the remaining four groups with 71 volatiles contributed to distinctions between orange and mandarin. Among the hybrids, the pattern of volatile detection frequency for hybrid FF-1-74-52 was virtually identical to sweet orange, and cluster analysis agreed with the classification. The number of average peaks were 55 to 62 in sweet oranges, 67 in FF-1-74-52, and 17 to 37 in tangerine and other hybrids. Quantity analysis of individual volatiles and chemical classes indicated that FF-1-74-52 and sweet oranges were rich in total volatile abundance, and almost all chemical classes including mono and sesquiterpenes, aldehydes, alcohols, ketones, and esters. This was especially true for ethyl butanoate, which contributes a fruity top note, and valencene and all sesquiterpene hydrocarbons, which only contribute to citrus flavor indirectly through their contribution to headspace partitioning. Two other hybrids, FF-1-75-55 and FF-1-76-51, each had some similarity to sweet oranges in several chemicals and classes, but not in the overall volatile profile. All three sweet orange-like hybrids met the standards for mandarins and oranges in soluble solids content, titratable acidity (TA), and the ratio. The above volatile and nonvolatile flavor chemical profile comparisons strongly support a proposal to classify FF-1-74-52 as a "sweet orange" commercially, and all three hybrids were previously shown to be more similar to sweet orange in their volatile profile than is 'Ambersweet'. 'Ambersweet' was a hybrid that was legally classified as a "sweet orange" in 1995 based on its volatile profile.
\end{abstract}

For orange juice $(\mathrm{OJ})$ use, although sugars and acids are essential for good taste, it is the volatiles that in fact determine the unique flavor of a cultivar (Shaw, 1991). The hybrids between mandarin and sweet orange and their descendants generally show various fruit size, shape, color, and flavor features somewhere in between that of the parents (Hearn, 1989; Yu et al., 2015). When a hybrid possesses quality characteristics similar to sweet orange, there is a precedent that it might be officially classified and commercialized as "sweet orange" (Moshonas et al., 1991). Swingle's taxonomic classification of citrus (Swingle and Reece, 1967), which has been widely supported by modern molecular technologic evidence, indicates that sweet orange is not the true species, but a hybrid, between pummelo (Citrus maxima) and mandarin (Velasco and Licciardello, 2014; Xu et al., 2013). Thus, if a hybrid of sweet orange and mandarin possesses similar quality attributes to sweet orange, it should not be a problem to be classified as a "sweet orange."

Only sweet orange can be used in OJ products without limitation under U.S. Food and Drug Administration standards

Received for publication 22 Dec. 2015. Accepted for publication 8 Mar. 2016. Mention of a trademark or proprietary product is for identification only and does not imply a guarantee or warranty of the product by the U.S. Department of Agriculture. The U.S. Department of Agriculture prohibits discrimination in all its programs and activities on the basis of race, color, national origin, gender, religion, age, disability, political beliefs, sexual orientation, and marital or family status.

${ }^{1}$ Corresponding author. E-mail: jinhe.bai@ars.usda.gov. of identity for orange juice. Only $10 \%$ of the juice from mandarins or citrus hybrids may be used in standard OJ products. Therefore, to permit unlimited use of a new hybrid in OJ products, the hybrid must be classified as "sweet orange" for the purpose of OJ production. 'Ambersweet' is the first hybrid designated as a "sweet orange" for both fresh and processing purposes (Florida Department of State, 1995), and its pedigree is $1 / 2$ sweet orange, $3 / 8$ mandarin, and $1 / 8$ grapefruit (Citrus paradisi) (Fig. 1) (Hearn, 1989). Moshonas et al. (1991) compared juice samples from 'Ambersweet' to multiple juice oranges, commercial juice samples, and several mandarins and tangelos for their volatile profiles, and confirmed that 'Ambersweet' had a similar volatile profile to that of sweet orange juice.

One of the objectives of the U.S. Department of Agriculture citrus breeding program is to provide the industry with highquality OJ cultivars, and especially cultivars with greater resistance or tolerance to the diseases Huanglongbing \{HLB [Candidatus Liberibacter asiaticus (CLas)] $\}$ and/or citrus canker (Xanthomonas axonopodis). The disease HLB causes great crop loss and degradation of fruit and juice quality (Baldwin et al., 2014; Stover and McCollum, 2011). Previously, we evaluated six sweet orange-like hybrids for their volatile profiles in comparison with 'Hamlin', the dominant early maturing sweet orange in Florida, and 'Ambersweet', the hybrid first classified as "sweet orange" and the common parent to all the hybrids (Bai et al., 2014). In that study, major 


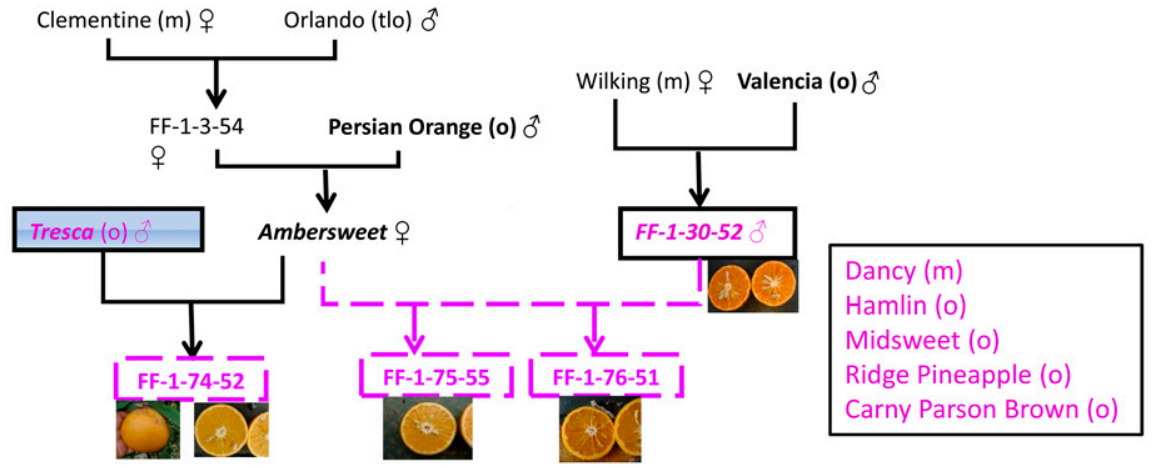

(m): mandarin (C. reticulata); (o): sweet orange (C. sinensis); (tlo): tangelo [mandarin -grapefruit (C. paradisi) hybrid]. sweet orange and grapefruit are also hybrids as follows: sweet orange (mandarin -pummelo hybrid) and grapefruit [pummelo (C. maxima) - sweet orange hybrid]

Fig. 1. Pedigree of the sweet orange-like hybrids and the commercial mandarin and orange cultivars used in this research to compare the target hybrids to the parents and the commercial references. FF-1-74-52, FF-1-75-55, and FF-1-76-51 were target hybrids; 'Tresca' and FF-1-30-52 (nontarget hybrid) were parents; and 'Dancy', 'Hamlin', 'Midsweet', 'Ridge Pineapple', and 'Carny Parson Brown' served as mandarin and sweet orange references.

aroma-active volatile compounds were investigated with cluster and principle component analyses, and the conclusion was that all candidates were similar enough to sweet orange in volatile profiles to be classified as "sweet orange." In the current research, we evaluated three leading sweet orange-like hybrids (selected due to fruit size, shape, and informal sensory tests) for their fruit volatile profiles, and compared them to five commercial sweet oranges, one mandarin and one hybrid breeding parents all with similar harvest maturity. The objective of this research was to determine whether the volatile profiles would support classification of the hybrids as "sweet orange."

\section{Materials and Methods}

Fruit MATERIALS AND JUICE PREPARAtion. Fruit harvested from the following commercial cultivars and hybrids were used for the experiments: Dancy tangerine (mandarin group), five sweet oranges (Hamlin, Midsweet, Ridge Pineapple, Carny Parson Brown, and Tresca), one orange hybrid as one of the parents, and three target sweet orange-like hybrids (Fig. 1), all grown at the A.H. Whitmore Citrus Research Foundation Farm in Leesburg, FL. The pedigree of the hybrids is shown in Fig. 1. Briefly, FF-1-75-55 and FF-1-76-51 are from a cross of 'Ambersweet' and FF-1-30-52. Their genetic background through three generations contains $1 / 2$ sweet orange, $7 / 16$ mandarin (not through sweet orange), and 1/16 grapefruit. FF-1-74-52 is from a cross of 'Ambersweet' and 'Tresca' sweet orange and its pedigree includes $3 / 4$ sweet orange, 3/16 mandarin (not through sweet orange), and 1/16 grapefruit (Fig. 1). Note that FF-1-30-52 was used as one of parents, but was not a target sweet orange-like hybrid. The fruit attributes were more similar to tangerine rather than sweet orange. Fruit samples were picked on 23 Jan. 2014, 30 Dec. 2014, and 27 Jan. 2015. Each sample included five defect-free fruit, and three replicates were collected for each genotype. For commercial cultivars, three replicates per cultivar were from three different trees. However, there was only one tree of each hybrid, thus the fruit were from three different branches/sections in the same tree. Fruit were stored overnight at room temperature $\left(25^{\circ} \mathrm{C}\right)$ before juicing.

Fruit samples were from HLBasymptomatic trees or asymptomatic branches in a symptomatic tree. The pathogen CLas was detected from all leaf samples except for FF-1-76-51 tree by using $\mathrm{Li}$ et al. (2006) method; however, CLas was not detected from any juice sample by Bai et al. (2013) and Zhao et al. (2015) methods. Although HLBsymptomatic fruit and juice are often associated with off-flavor and other negative quality attributes, HLB-asymptomatic fruit and juice usually do not show flavor and quality defects, especially when CLas level is not detectable (Baldwin et al., 2010; Zhao et al., 2015).

Fruit were hand washed using a commercial fruit detergent (Fruit Cleaner 395; JBT FoodTech, Lakeland, FL), and dried using paper towels. Then fruit were gently juiced by hand, to avoid excessive peel oil entering the juice, using a kitchen juicer with an automatic self-reversing reamer (Oster model 3183; Household Appliance Sales and Service, Niles, IL). A 6-mL volume of each juice sample was pipetted into a $20-\mathrm{mL}$ vial and was crimp capped with a silicone septum (Gerstel, Linthicum, MD) for gas chromatography-mass spectrometry (GC-MS) analysis, and $50 \mathrm{~mL}$ of juice per sample was transferred into a glass bottle for sugar and acid analysis. Sample vials/bottles were stored at $-80{ }^{\circ} \mathrm{C}$ until analyzed.

HeadspaCe SAMPling ANd GC-MS anAlysis. Frozen sample vials were thawed under tap water and loaded into the autosampler (model MPS2; Gerstel) equipped with a cooled tray holder [a cooling plate (Laird Tech, Göteborg, Sweden) controlled by a Peltier thermostat (CTC Analytics, Zwingen, Switzerland)]. Samples were held 0 to $16 \mathrm{~h}$ at $4{ }^{\circ} \mathrm{C}$ in the cooled tray until analyzed. For analysis, juice samples were incubated for $30 \mathrm{~min}$ at $40{ }^{\circ} \mathrm{C}$. A $2-\mathrm{cm}$ solid phase microextraction (SPME) fiber (50/30 $\mu \mathrm{m}$ DVB/Carboxen/PDMS; Supelco, Bellefonte, PA) was then exposed to the headspace for $30 \mathrm{~min}$ at $40{ }^{\circ} \mathrm{C}$. After exposure, the SPME fiber was inserted into the injector of a GC-MS (model 6890; Agilent, Santa Clara, $\mathrm{CA})$ to desorb the extract for $15 \mathrm{~min}$ at $250{ }^{\circ} \mathrm{C}$. The GC-MS equipment and settings were DB-5 (60 m length, $0.25 \mathrm{~mm}$ i.d., $1.00 \mu \mathrm{m}$ film thickness; J\&W Scientific, Folsom, CA) columns, coupled with a MS detector (5973 N; Agilent). The column oven was programmed to increase at $4^{\circ} \mathrm{C} \cdot \mathrm{min}^{-1}$ from the initial 40 to $230{ }^{\circ} \mathrm{C}$, then ramped at $100{ }^{\circ} \mathrm{C} \cdot \mathrm{min}^{-1}$ to $260{ }^{\circ} \mathrm{C}$ and held for $11.7 \mathrm{~min}$ for a total run time of $60 \mathrm{~min}$. Helium was used as carrier gas at a flow rate of $1.5 \mathrm{~mL} \cdot \mathrm{min}^{-1}$. Inlet, ionizing source, and transfer line were kept at 250, 230, and $280{ }^{\circ} \mathrm{C}$, respectively. Mass units were monitored from 30 to $250 \mathrm{~m} / \mathrm{z}$ and ionized at $70 \mathrm{eV}$. Data were collected using a data system (ChemStation G1701 AA; Hewlett-Packard, Palo Alto, CA). A mixture of C-5 to C-18 n-alkanes was run at the beginning of each day to calculate retention indices (RIs) (Bai et al., 2014).

VOLATILE COMPOUND IDENTIFICATION AND QUANTIFICATION. Volatile compounds were identified by comparison of their 
mass spectra with authentic volatile compound standards, and/ or library entries (NIST/EPA/NIH Mass Spectral Library, version 2.0d; National Institute of Standards and Technology, Gaithersburg, MD), as well as by comparing RIs with published RIs (Adams and Brown, 2007; Kondjoyan and Berdagué, 1996). Quantification for 21 selected major aroma active volatile components was conducted by using a peak size vs. concentration curve from serially diluted standard solutions to provide five concentrations for each component (Bai et al., 2002; Baldwin et al., 2010). Briefly, a standard compound was dissolved in pure methanol and the mixture was then introduced into a sugar equivalent deodorized orange juice (diluted "pumpout" concentrate) (Plotto et al., 2004). The range of concentrations in the standard curve for each compound covered the concentrations found in the samples.

ANALYSIS OF SUGARS AND ACIDS. Juice samples were centrifuged at $10,000 g_{n}$ for $15 \mathrm{~min}$. The supernatant was used for all sugar and acid analysis. TA was determined by titrating to $\mathrm{pH}$ 8.1 with $0.1 \mathrm{~N} \mathrm{NaOH}$ using an autotitrator (DL50; Mettler Toledo, Columbus, OH). Soluble solids content (SSC) was determined using a refractometer (PR-101; Atago, Tokyo, Japan).

For analysis of individual sugars and acids, $10 \mathrm{~mL}$ of supernatant was passed through a solid-phase extraction column (C-18 Sep-Pak; Waters, Milford, MA) followed by a filter (0.45 $\mu \mathrm{m}$; Waters). Sugar analysis was performed by highperformance liquid chromatography (HPLC) with a pump (Spectra System P4000; Thermo Separation Products, San Jose, CA) and a refractive index detector (1100 Series; Agilent) equipped with a $300 \times 6.5-\mathrm{mm}$ column (Sugar-Pak, Waters). The mobile phase was $10^{-4} \mathrm{M}$ ethylenediaminetetraacetic acid disodium calcium salt (CaEDTA) with a $0.5 \mathrm{~mL} \cdot \mathrm{min}^{-1}$ flow rate at $90{ }^{\circ} \mathrm{C}$.

Organic acids (citrate and malate) were analyzed using the same HPLC as above equipped with an organic acid column (OA-1000 Prevail; Alltech, Flemington, $\mathrm{NJ}$ ) with a flow rate of $0.2 \mathrm{~mL} \cdot \mathrm{min}^{-1}$ at $35^{\circ} \mathrm{C}$ and a mobile phase of $0.01 \mathrm{~N} \mathrm{H}_{2} \mathrm{SO}_{4}$ and an ultraviolet detector (Spectra System ultraviolet 6000 LP; Thermo Separation Products). The injection volume was $20 \mu \mathrm{L}$ using an autosampler (Series 200; PerkinElmer, Norwalk, CT).

Statistical analyses. SAS (version 9.3; SAS Institute, Cary, NC) was used for data analysis. Analysis of variance (ANOVA) was performed by using the ANOVA procedure. Cluster analysis (PROC CLUSTER) and principle component analysis (PCA) were used to classify the cultivars/hybrids based on detection frequency of volatiles. Heatmaps were generated based on the average values by using Excel (version 15; Microsoft, Redmond, WA).

\section{Results and Discussion}

SUGARS AND ACIDS. Florida maturity standard for oranges harvested between 16 Nov. and 31 July are SSC $>8.5 \%$, TA or acid $>0.4 \%$, and $\mathrm{SSC} / \mathrm{TA}$ ratio $>10.25$ when $\mathrm{SSC}$ is low, but the ratio standard decreases to $>9$ if $\mathrm{SSC}$ is higher than $11 \%$, (Florida Senate, 2011). The standard for tangerines, which include mandarins and hybrids in the same period of time, are $\mathrm{SSC}>8.75 \%$, and $\mathrm{SSC} / \mathrm{TA}$ ratio $>7.25$ to 8.25 depending on SSC level, and there is no standard for TA (Florida Senate, 2011). All genotypes in this research met the tangerine standards, and most of them also met the orange standards regarding SSC, TA, and SSC/TA ratio (Table 1). However, two oranges, 'Ridge Pineapple' and 'Midsweet', which are later maturing than 'Hamlin', and the nontarget hybrid parent, FF-130-52, did not meet the minimum orange standard in SSC/TA ratio (Table 1). Eventually, the acid contents in the two oranges should decrease to achieve $\mathrm{SSC} / \mathrm{TA}$ ratio standards by delaying harvest time (Bai et al., 2016). All hybrid selections, FF-1-7452, FF-1-75-55, and FF-1-76-51, met the SSC and TA standards (Table 1).

Florida juice standard requires 10.25 or greater SSC/TA ratio (Ritenour, 2014), and the OJ industry has established SSC/ TA of 12.5 to 19.5 for juice designated as high quality (Matthews, 1994). Thus, all targeted hybrids met the juice standard, and FF-1-74-52 and FF-1-76-51 with SSC/TA ratios of 15.9 and 13.5 , respectively, fell into the high-quality juice range (Table 1).

Other attributes were exhibited as expected: sucrose:glucose: fructose ratios were in a 2:1:1 ratio; $\mathrm{pH}$ values were all below 4.00 with high acidity; citric acid was the major acid and malic acid levels were less than $10 \%$ of citric acid in all samples (Table 1). There were no substantial differences between oranges, mandarin, and hybrids (Table 1).

Overall volatile Profiles. A total of 114 volatiles were detected and separated into seven groups (Fig. 2) based on the frequency of detection in the nine samples of each genotype (cultivar or hybrid selection). Twelve volatiles comprised Group 1 in which all volatiles were detected from all cultivars and hybrids, with detection in at least five of the nine samples in all genotypes and detection in all samples for most genotypes; 15 volatiles comprised Group 6, in which volatiles were detected in only some samples for all genotypes without a clear pattern between oranges, mandarin and hybrids; and 16 volatiles comprised Group 7, which were rarely detected in any genotype. These three groups, with 43 volatile components, were not useful in distinguishing sweet orange vs. mandarin. On the other hand, the rest of the 71 volatiles were useful in distinguishing sweet oranges vs. mandarin. The 34 compounds comprising Group 2 were detected in all oranges and the hybrid FF-1-74-52, with detection in five or more of the samples from each of these genotypes, but had less consistent detection in 'Dancy' and the other hybrids; this group was further divided into four subgroups based on the frequency of detections in samples of 'Dancy' and three hybrids. Subgroup 2A was composed of volatiles in which each volatile was detected in fewer than three samples for only one of the four genotypes not showing a sweet orange profile; then the detection frequency in these genotypes decreased successively in the order of $2 \mathrm{~B}, 2 \mathrm{C}$, and 2D. The 12 compounds which comprised subgroup 2D were not detected in the four genotypes not showing a sweet orange profile except that one volatile in one genotype was detected in two of the nine samples (Fig. 2). Group 3 was composed of 21 volatiles which were detected in FF-1-74-52 with 13 of these volatiles also detected in oranges, but were not detected in 'Dancy' or the other hybrids. The five volatiles comprising Group 4 were detected in some samples of all oranges but never in 'Dancy' nor in any hybrid selection; and the 11 volatiles comprising Group 5 were not detected in oranges or the hybrid FF-1-74-52, but were detected in 'Dancy' and some of the other hybrids (Fig. 2). The overall volatile profile indicates that FF-1-74-52 had all of the typical sweet orange volatiles, but no distinctive mandarin compounds (Fig. 2). Cluster analysis by using the detection frequency data divided the citrus genotypes to two large clusters (Fig. 2): FF-1-74-52 was 


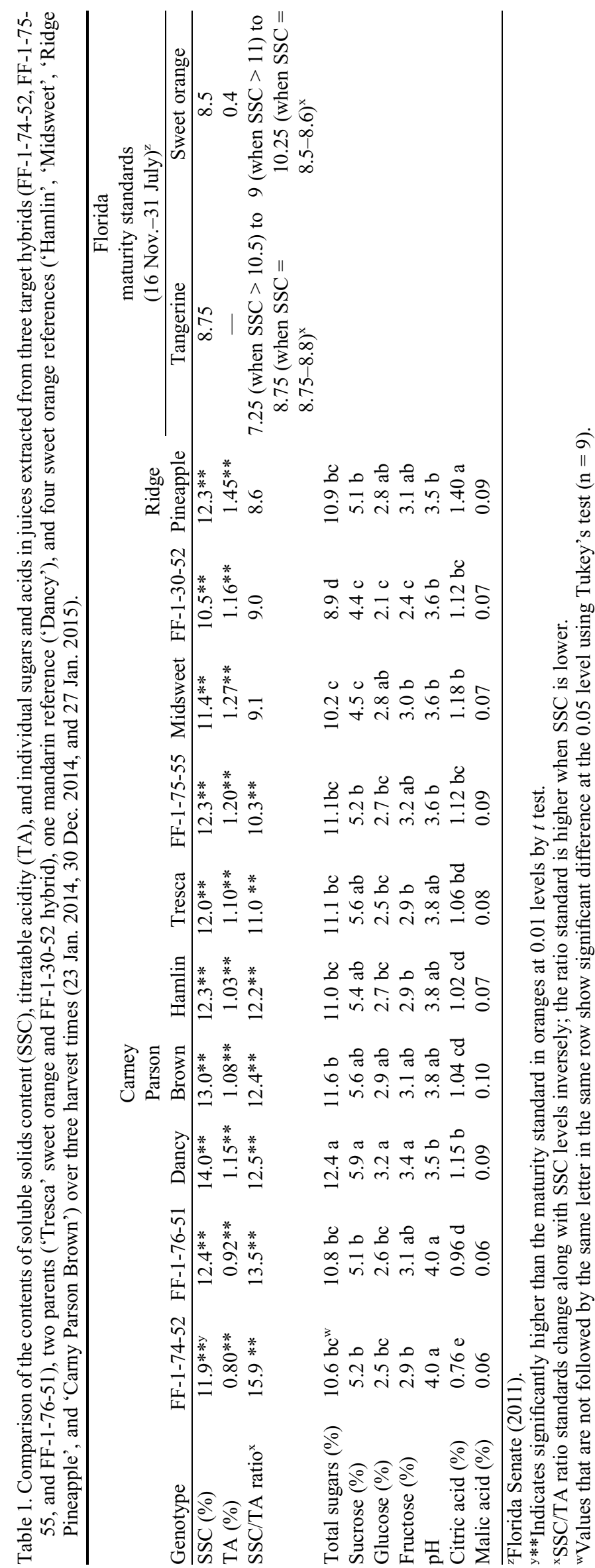

clustered together with oranges and mostly closed to the parent 'Tresca' (Fig. 1); FF-1-75-55 and FF1-76-51 were clustered together with 'Dancy' tangerine, and the mandarin-like parent hybrid, FF-1-30-72 (Figs. 1 and 2). PCA results provided a similar separation as did cluster analysis did (data not shown).

Average peak number per sample was $55-62$ in sweet oranges, 67 peaks were found in FF-1-74-52, but only 17-37 were found in mandarin and other hybrids (Table 2). Similar patterns were also found for the total peak size in different citrus types. The total size per sample was $1323-1667 \times 10^{7}$ total ion currents (TIC) in sweet orange, in comparison with FF1-74-52 with 2127 TIC, and 'Dancy' and other hybrids with lower levels of 259-1017 TIC (Table 3).

IMPORTANT AROMA CONTRIBUTORS AND THE CHEMICAL CLASSES. In Table 2, 17 important aroma contributors to orange juice were highlighted out of the total 114 compounds which usually are suggested to have a positive impact with positive log odor units on the flavor profile (Moshonas et al., 1991; Perez-Cacho and Rouseff, 2008a; Pérez-López and Carbonell-Barrachina, 2006; Shaw, 1991). However, it has been shown that in tomato volatile compounds with negative odor units might contribute to the overall flavor as background notes (Baldwin et al., 2008). Interaction between volatiles, as well as between volatile and nonvolatile components may change our perception of fruit aromas and thus deviate from accepted importance of certain volatiles in fruit aroma and flavor (Auvray and Spence, 2008; Baldwin et al., 2008; Frank and Byram, 1988).

The major monoterpene hydrocarbons were D-limonene, $\beta$-myrcene, and $\alpha$-pinene (Table 2 ), which are mainly contributed from peel oil of citrus fruit (Dugo et al., 2011). Generally, D-limonene represents $90 \%$ to $96 \%$ of total peel oil in oranges, but in mandarins, the content is cultivar dependent: 'Nules' and 'Du Japon' were as high as $>95 \%$, but 'Nasnaran', 'Kunembo', and 'Willow Leaf' were as low as $56 \%$ to $65 \%$ (Lota et al., 2001). 'Dancy' and FF-1-74-52 had comparable amounts of D-limonene to oranges, though the other hybrids had substantially lower D-limonene, with less than $2 / 3$ the level of oranges (Table 2). Contents of $\beta$-myrcene, $\alpha$-pinene (Table 2) and total monoterpene hydrocarbons (Table 4) followed similar trends as did D-limonene although they had smaller peaks. D-limonene has been suggested to be one of the most important contributors to orange flavor (Shaw, 1991); however, others indicate that it is necessary for orange aroma, but not a key flavor impact compound (Plotto et al., 2004), except that high concentrations are associated with development of off-odors due to oxidation derivatives in processed juice (Perez-Cacho and Rouseff, 2008a). Nevertheless, the great abundance of terpenes, such as D-limonene and valencene, can indirectly affect the perception of other volatiles through their effects on volatility, which alters headspace partitioning (Plotto et al., 2008). $\beta$-Myrcene was reported to negatively influence citrus and orange juice flavor (Ahmed et al., 1978; Miyazaki et al., 2012). $\alpha$-Pinene is a positive contributor to orange juice aroma (Shaw, 1991). Sesquiterpene hydrocarbons were the next largest group in oranges and FF-1-74-52, and the major volatile in the group was valencene (Tables $2-4$ ), which possesses a weak, citrus-like aroma (Plotto et al., 2004; Shaw, 1991). Nevertheless, very little of these compounds were detected in 'Dancy' and other hybrids (Tables 2-4). It is remarkable that valencene and sesquiterpene levels varied almost 100 -fold between oranges and nonoranges (Tables 2-4). However, as with other volatiles, valencene or sesquiterpene levels alone are not absolute 

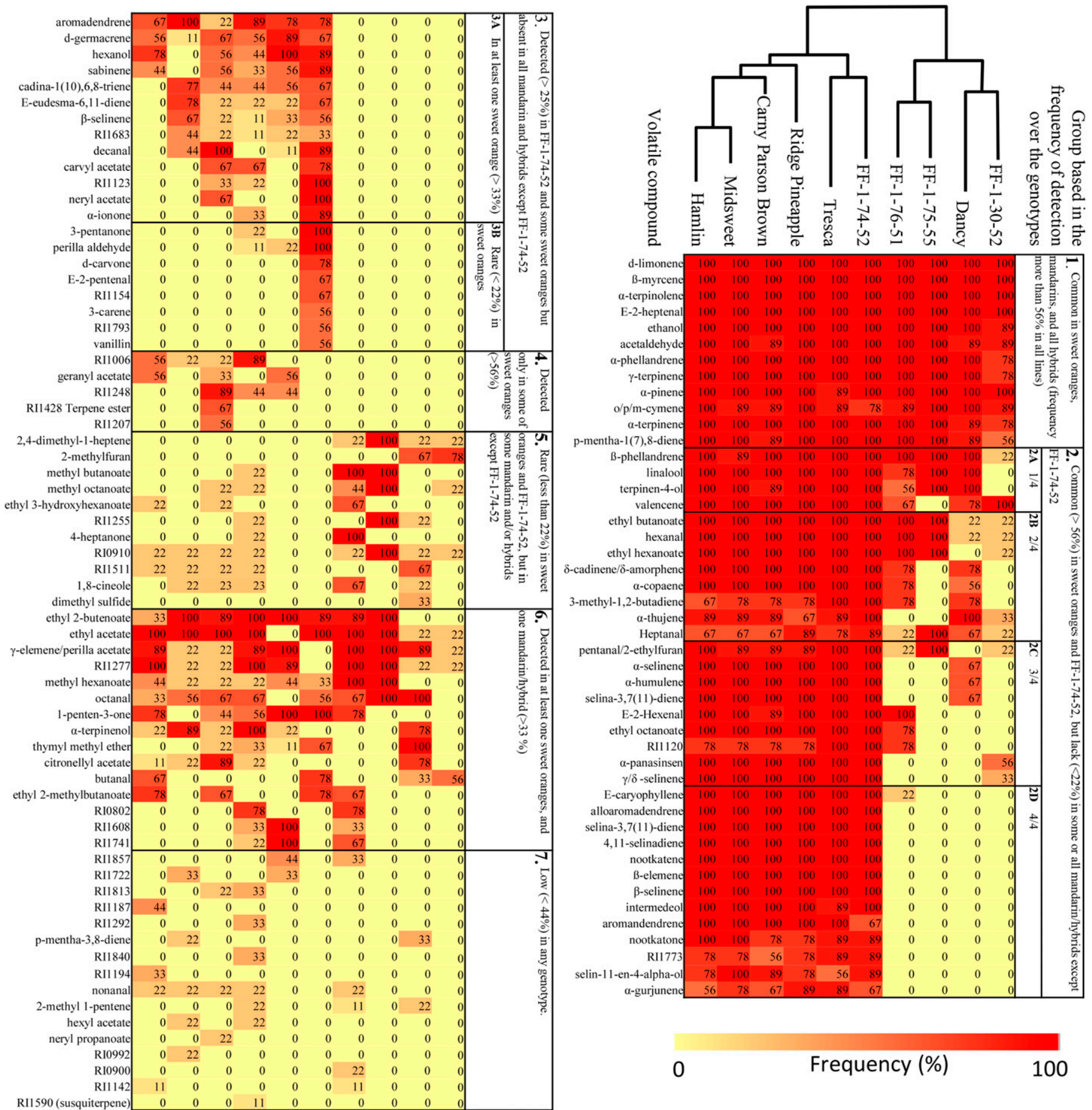

Fig. 2. Comparison of the detection frequency of volatiles in juices extracted from three target hybrids (FF-1-74-52, FF-1-75-55, and FF-1-76-51), two parents ('Tresca' sweet orange and FF-1-30-52 hybrid), one mandarin reference ('Dancy'), and four sweet orange references ('Hamlin', 'Midsweet', 'Ridge Pineapple', and 'Carny Parson Brown'). Fruit were harvested on 23 Jan. 2014, 30 Dec. 2014, and 27 Jan. 2015, and each harvest had three replicates (n =9). Cluster analysis was run based on the detection frequency of 114 volatiles. Unknown compounds were labeled as "RI" plus a four-digit retention index of the peaks.

indicators that fruit and resulting juice will be perceived as sweet orange. Yu et al. (2015) observed that 'Murcott' and 'Temple' mandarin hybrids differed in valencene levels with the former producing little valencene, which agreed with the results in this research, and the latter producing substantial amounts of valencene. Valencene synthase (Cstps1) in the mevalonate pathway was found to be the key step in valencene production and was found differ in expression between 'Murcott' and 'Temple' hybrids (Yu et al., 2015). Other important terpene compounds included two terpene alcohols, linalool and terpinen-4-ol, and one terpene acetone, D-carvone (Table 2). Linalool followed a similar pattern as the above monoterpenes and terpinen-4-ol had little difference among all the genotypes (Table 2). D-Carvone will be addressed later as compounds 


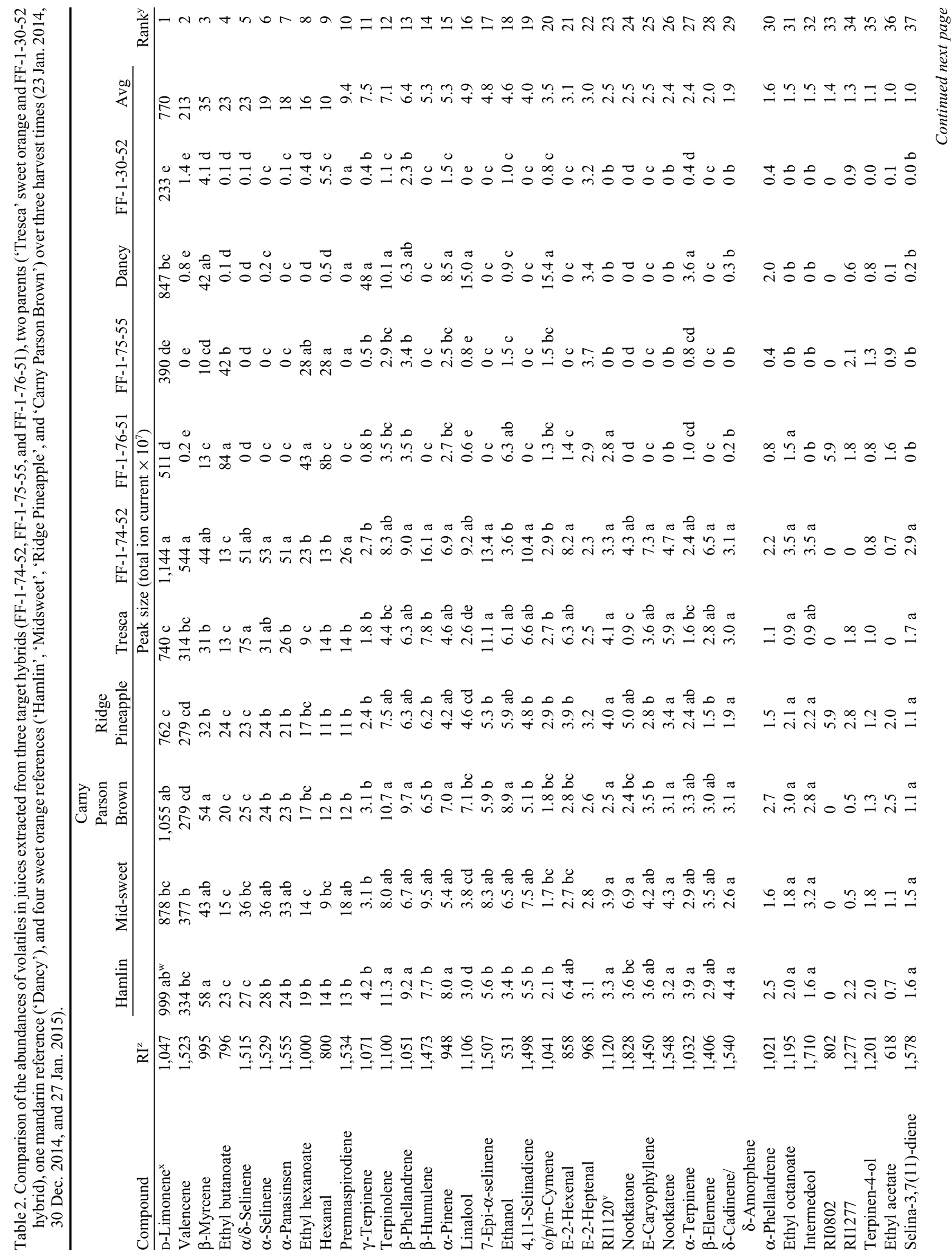




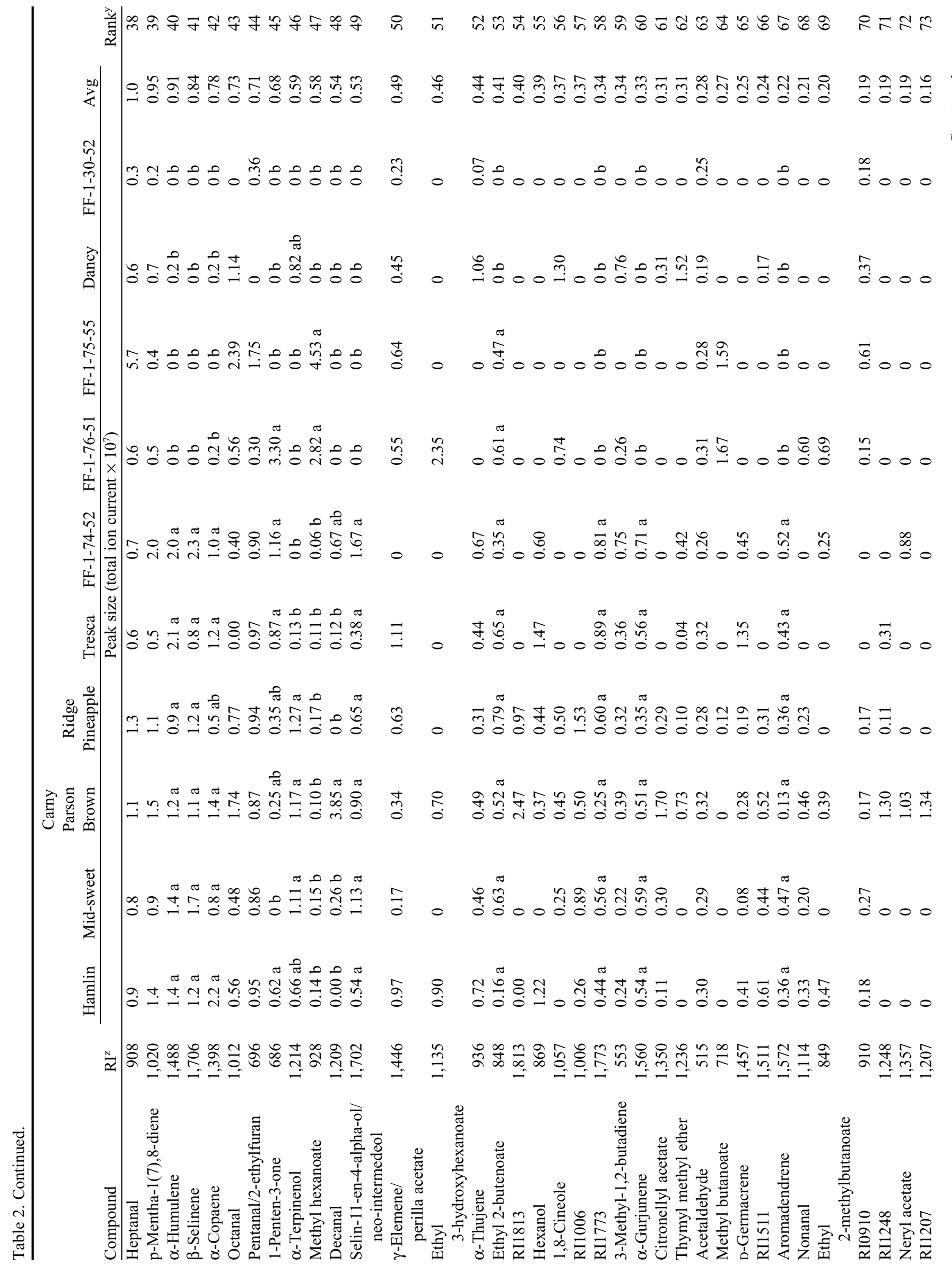




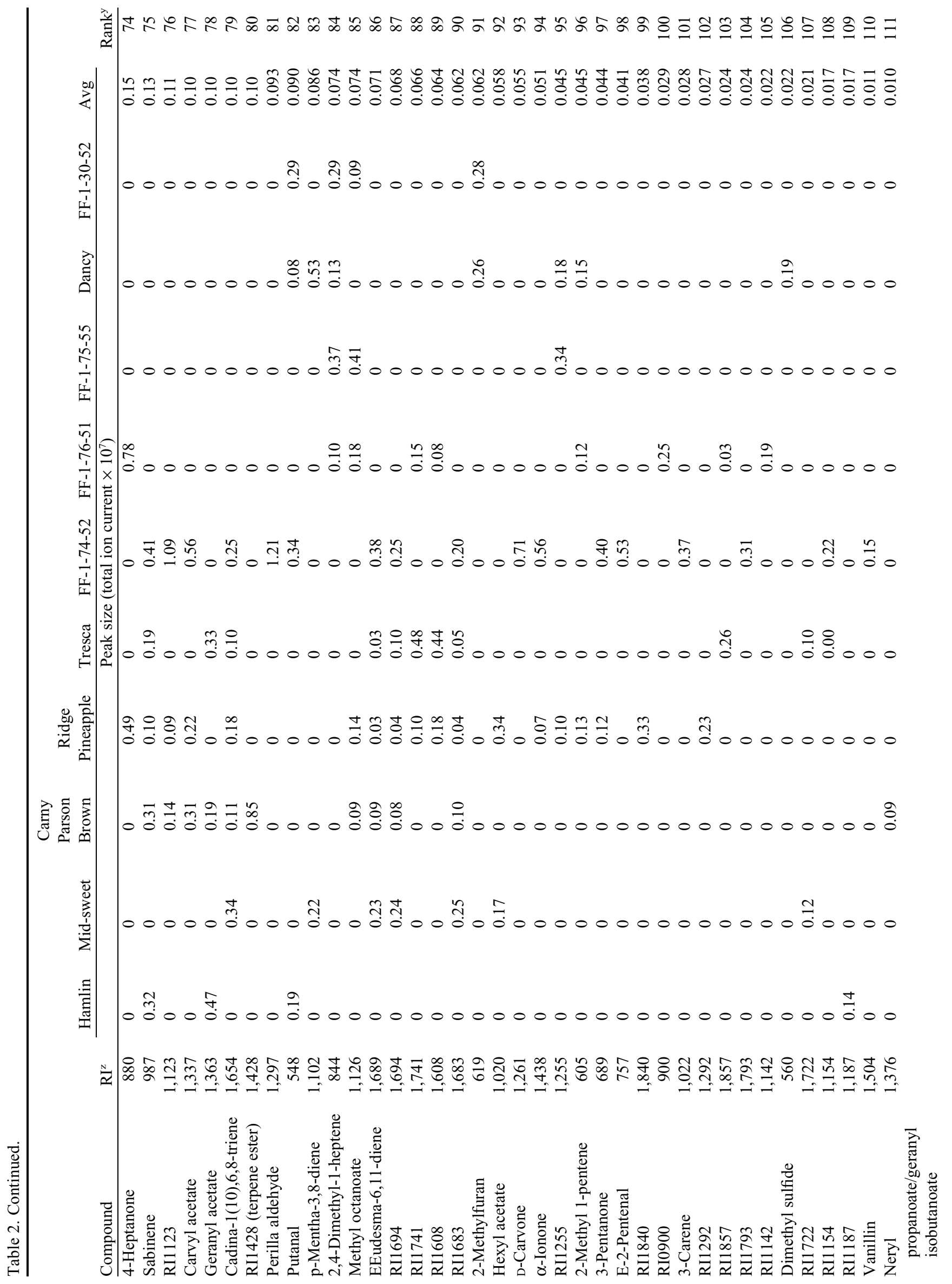




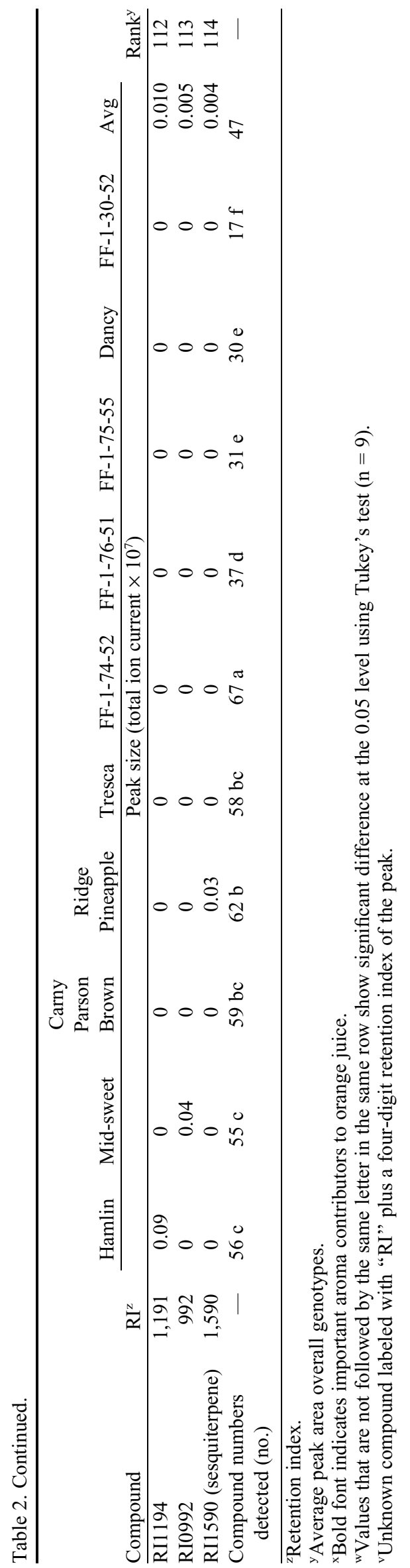

detected only in FF-1-74-52, but not any other genotypes. Linalool is sometimes reported to make a positive contribution to typical orange flavor although it is not considered a critical odor impact compound (Ahmed et al., 1978). Terpinen-4-ol, together with linalool and other terpene alcohols were reported to add fruity and mint aroma to orange juice (Högnadóttir and Rouseff, 2003).

Ethyl esters are among the most important aroma components which give the fruity top notes in orange juice including ethyl butanoate, ethyl acetate, methyl butanoate, and ethyl 3-hydroxyhexanoate (Perez-Cacho and Rouseff, 2008; Plotto et al., 2008; Shaw, 1991). Ethyl butanoate is the major contributor to "fruity" aroma, and other ethyl esters enhanced the fruity and sweet notes (Shaw, 1991). A substantial amount of ethyl butanoate was found in all orange and FF-1-74-52 juices; however, the amounts were extremely high in FF-1-7555 and FF-1-76-51 (2- to 3-fold that of oranges) which made the hybrids fruity and sweet, but ethyl butanoate was barely detected in 'Dancy' and FF-1-30-52.

The aliphatic aldehydes in orange juice, which often contribute citrus-like fruity and green notes, include acetaldehyde, octanal, nonanal, and decanal (Perez-Cacho and Rouseff, 2008a; Shaw, 1991). Four other aldehydes showed no apparent pattern relating to presence in sweet orange vs. mandarin (Table 2).

Ethanol is an abundant compound. It is expected to contribute little directly to juice flavor, but might affect perception of other volatile compounds (Perez-Cacho and Rouseff, 2008). The ethanol concentration in 'Dancy' and two hybrids, FF-175-55 and the nontarget (the parent hybrid not similar to sweet orange) FF-1-30-52, was less than half that of oranges and the other two hybrids (Table 2).

There were six compounds that were detected in FF-1-74-52 but not in any other cultivars or hybrids [Fig. 2 (subgroup 3B)]. D-Carvone possesses a caraway-or dill-like aroma and flavor that is objectionable when added to synthetic mixtures having orange-like aroma. It has been rarely reported and was associated with oxidative decomposition of orange juice in storage (Ahmed et al., 1978). E-2-pentenal and vanillin were detected from orange juice by Plotto et al. (2004) with levels near detection thresholds, and generally they contribute positive fruity aromas (Tandon et al., 2000). 3-Carene is a trace volatile derived from citrus peel oil in both mandarin and orange juices in some reports (Moshonas and Shaw, 1997), while others indicate that the compound does not exist in orange peel oil (Dugo et al., 2011). Several typical mandarin/tangerine volatiles, such as methyl $N$-methyl anthranilate, thymol, and thymol methyl ether were not found in any genotype.

Classification of Citrus. The taxonomy of subgenus Citrus is fairly controversial, confusing, or inconsistent. Barrett and Rhodes (1976) suggested that there are only three "basic" true species of Citrus as defined by Swingle and Reece (1967): citron (Citrus medica), mandarin, and pummelo. Other cultivated Citrus species, such as sweet orange, grapefruit, lemon (Citrus limon), lime (Citrus aurantifolia), etc. are hybrids derived from these true species, with some contribution from species of the subgenus Papeda. This concept has received increasing support in recent years from data derived from molecular markers and complete genomic sequence data (Barkley et al., 2006; Federici et al., 1998; Nicolosi et al., 2000; Wu et al., 2014).

Sweet orange is a hybrid, between pummelo and mandarin. It has genes that are $\approx 25 \%$ pummelo and $\approx 75 \%$ mandarin, and 


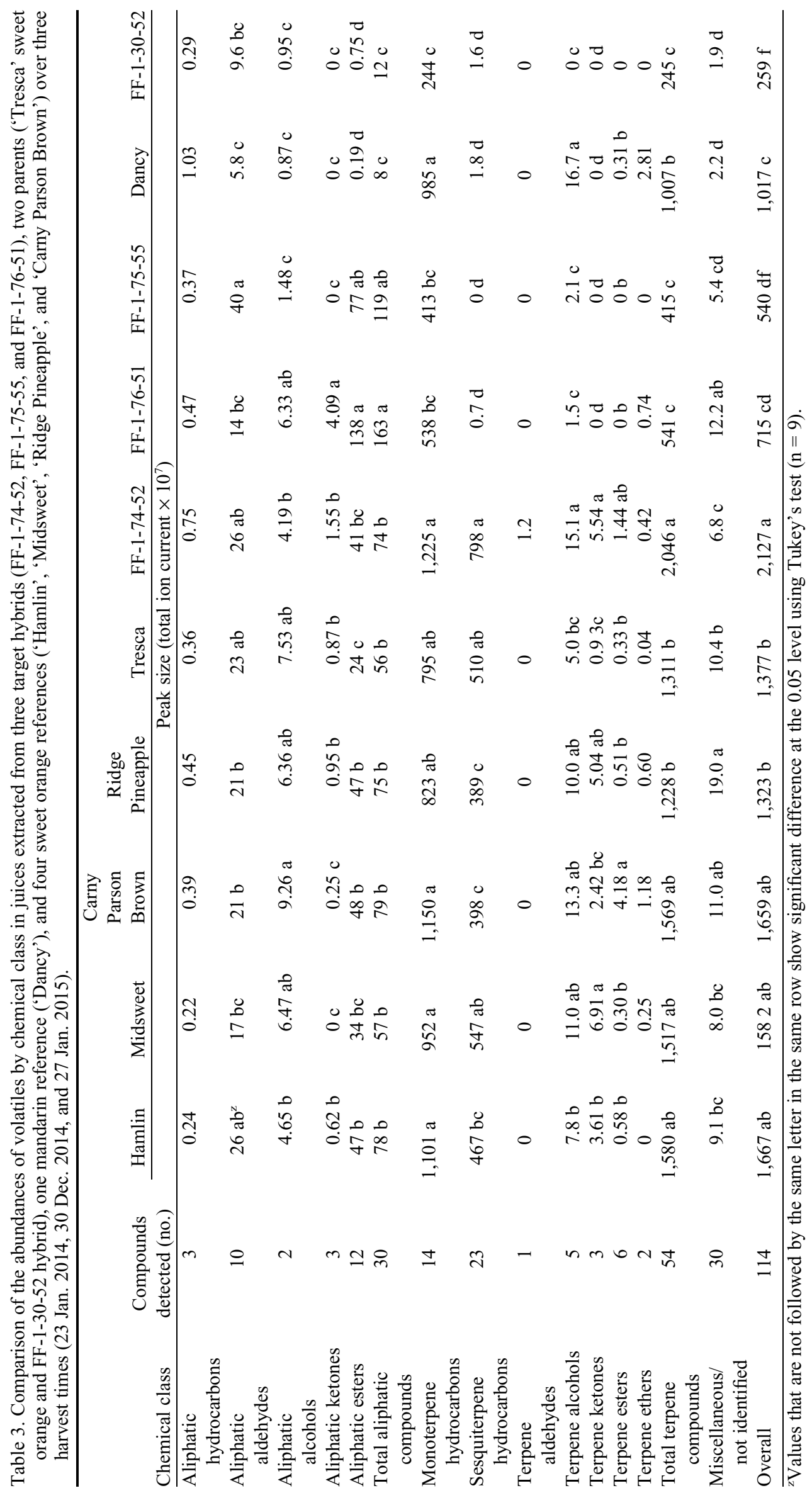


Table 4. Relative abundances of d-limonene and valencene, and total terpene compounds in juices extracted from three target hybrids (FF-1-7452, FF-1-75-55, and FF-1-76-51), two parents ('Tresca' sweet orange and FF-1-30-52 hybrid), one mandarin reference ('Dancy'), and four sweet orange references ('Hamlin', 'Midsweet', 'Ridge Pineapple', and 'Carny Parson Brown') over three harvest times (23 Jan. 2014 , 30 Dec. 2014, and 27 Jan. 2015).

\begin{tabular}{|c|c|c|c|c|c|c|c|c|c|c|}
\hline Chemical class & Hamlin & Midsweet & $\begin{array}{l}\text { Carny } \\
\text { Parson } \\
\text { Brown }\end{array}$ & $\begin{array}{c}\text { Ridge } \\
\text { Pineapple }\end{array}$ & Tresca & FF-1-74-52 & FF-1-76-51 & FF-1-75-55 & Dancy & FF-1-30-52 \\
\hline $\begin{array}{l}\text { Monoterpene } \\
\text { hydrocarbons } \\
\text { (peak area) }\end{array}$ & $1,101 \mathrm{a}^{\mathrm{z}}$ & $952 \mathrm{a}$ & $1,150 \mathrm{a}$ & $823 \mathrm{ab}$ & $795 \mathrm{ab}$ & $1,225 \mathrm{a}$ & $538 \mathrm{bc}$ & $413 \mathrm{bc}$ & $985 \mathrm{a}$ & $244 \mathrm{c}$ \\
\hline $\begin{array}{l}\text { Contribution of } \\
\text { D-limonene }(\%)\end{array}$ & $91 \mathrm{a}$ & $92 \mathrm{a}$ & $92 \mathrm{a}$ & $93 \mathrm{a}$ & $93 \mathrm{a}$ & 93 a & $95 \mathrm{a}$ & $95 \mathrm{a}$ & $86 \mathrm{~b}$ & $95 \mathrm{a}$ \\
\hline $\begin{array}{l}\text { Contribution of } \\
\text { non-D-limonene } \\
\text { compounds }(\%)\end{array}$ & $9 \mathrm{~b}$ & $8 \mathrm{~b}$ & $8 \mathrm{~b}$ & $7 \mathrm{~b}$ & $7 \mathrm{~b}$ & $7 \mathrm{~b}$ & $5 \mathrm{~b}$ & $5 \mathrm{~b}$ & $14 \mathrm{a}$ & $5 \mathrm{~b}$ \\
\hline $\begin{array}{l}\text { Sesquiterpene } \\
\text { hydrocarbons } \\
\text { (peak area) }\end{array}$ & $467 \mathrm{bc}$ & $547 \mathrm{ab}$ & $398 \mathrm{c}$ & $389 \mathrm{c}$ & $510 \mathrm{ab}$ & 798 a & $1 \mathrm{~d}$ & $0 \mathrm{~d}$ & $2 \mathrm{~d}$ & $2 \mathrm{~d}$ \\
\hline $\begin{array}{l}\text { Contribution of } \\
\text { valencene }(\%)\end{array}$ & $72 \mathrm{a}$ & $69 \mathrm{a}$ & $70 \mathrm{a}$ & $72 \mathrm{a}$ & $62 \mathrm{ab}$ & $68 \mathrm{a}$ & $34 \mathrm{~b}$ & - & $44 \mathrm{~b}$ & $88 \mathrm{a}$ \\
\hline $\begin{array}{l}\text { Contribution of } \\
\text { non-valencene } \\
\text { compounds }(\%)\end{array}$ & $28 \mathrm{~b}$ & $31 \mathrm{~b}$ & $30 \mathrm{~b}$ & $28 \mathrm{~b}$ & $38 \mathrm{ab}$ & $32 \mathrm{~b}$ & $66 \mathrm{a}$ & - & $56 \mathrm{a}$ & $12 \mathrm{~b}$ \\
\hline $\begin{array}{l}\text { Total terpene } \\
\text { compounds } \\
\text { (peak area) }\end{array}$ & $1,580 \mathrm{ab}$ & $1,517 \mathrm{ab}$ & $1,569 \mathrm{ab}$ & $1,228 \mathrm{~b}$ & $1,311 \mathrm{~b}$ & $2,046 \mathrm{a}$ & $541 \mathrm{c}$ & $415 \mathrm{c}$ & $1,007 \mathrm{~b}$ & $245 \mathrm{c}$ \\
\hline $\begin{array}{c}\text { Contribution of } \\
\text { D-limonene }+ \\
\text { valencene }(\%)\end{array}$ & $84 \mathrm{~b}$ & $83 \mathrm{~b}$ & $85 \mathrm{~b}$ & $85 \mathrm{~b}$ & $80 \mathrm{~b}$ & $82 \mathrm{~b}$ & $95 \mathrm{a}$ & $94 \mathrm{a}$ & $84 \mathrm{~b}$ & $95 \mathrm{a}$ \\
\hline $\begin{array}{l}\text { Contribution of } \\
\text { other than } \\
\text { D-limonene and } \\
\text { valencene }(\%)\end{array}$ & $16 \mathrm{a}$ & $17 \mathrm{a}$ & $15 \mathrm{a}$ & $15 \mathrm{a}$ & $20 \mathrm{a}$ & $18 \mathrm{a}$ & $5 \mathrm{~b}$ & $6 \mathrm{~b}$ & $16 \mathrm{a}$ & $5 \mathrm{~b}$ \\
\hline
\end{tabular}

${ }^{\mathrm{z}}$ Values that are not followed by the same letter in the same row show significant difference at the 0.05 level using Tukey's test $(\mathrm{n}=9)$.

hybridized over multiple generations (Velasco and Licciardello, 2014; Xu et al., 2013; Wu et al., 2014). Thus, if a hybrid of sweet orange and mandarin possesses similar quality attributes to sweet orange in fruit size, color, and taste, then the classification as an "sweet orange" is generally by flavor.

An important objective for the sweet orange-like citrus breeding program was to find high-quality juice cultivars with resistance or tolerance to HLB. Most of the trees of the tested genotypes have shown HLB symptoms in the grove, however, the tree of FF-1-76-51 continues to be CLas free in tests of leaf samples (Li et al., 2006). It will also likely prove susceptible, but may possess a commercially useful level of tolerance.

In conclusion, FF-1-74-52 was essentially indistinguishable from sweet orange from all of the following tests: SSC, TA, and SSC/TA ratio; cluster analysis based on frequency of volatile detection; heat map comparison based on grouping of distribution and frequency of volatile detection; and comparison of important orange and tangerine volatile contributors. FF-1-7555 had some similar flavor attributes to sweet oranges and was more similar to sweet orange than was 'Ambersweet' in an earlier analysis (Bai et al., 2014); however, it lacked at least $20 \%$ of the volatile compounds (Group 2 in Fig. 2) present in sweet oranges and FF-1-74-52. Further research, including sensory studies, are needed to evaluate the contribution of those missing volatiles in the aroma profiles.

\section{Literature Cited}

Adams, J.B. and H.M. Brown. 2007. Discoloration in raw and processed fruits and vegetables. Crit. Rev. Food Sci. Nutr. 47:319-333.

Ahmed, E.M., R.A. Dennison, and P.E. Shaw. 1978. Effect of selected oil and essence volatile components on flavor quality of pump out orange juice. J. Agr. Food Chem. 26:368-372.

Auvray, M. and C. Spence. 2008. The multisensory perception of flavor. Conscious. Cogn. 17:1016-1031.

Bai, J., E. Baldwin, H.-L. Liao, W. Zhao, I. Kostenyuk, J. Burns, and M. Irey. 2013. Extraction of DNA from orange juice, and detection of bacterium Candidatus Liberibacter asiaticus by real-time PCR. J. Agr. Food Chem. 61:9339-9346.

Bai, J., E.A. Baldwin, G. McCollum, A. Plotto, J.A. Manthey, W.W. Widmer, G. Luzio, and R. Cameron. 2016. Changes in volatile and non-volatile flavor chemicals of 'Valencia' qrange juice over the harvest seasons. Foods 5:47-63.

Bai, J., E. Baldwin, E. Stover, R. Driggers, and J. Hearn. 2014. Volatile profile comparison of USDA sweet orange-like hybrids versus 'Hamlin' and 'Ambersweet'. HortScience 49:1262-1267.

Bai, J., R.D. Hagenmaier, and E.A. Baldwin. 2002. Volatile response of four apple varieties with different coatings during marketing at room temperature. J. Agr. Food Chem. 50:7660-7668.

Baldwin, E., J. Bai, A. Plotto, and M. Ritenour. 2014. Citrus fruit quality assessment: Producer and consumer perspectives. Stewart Postharvest Rev. 10(2):1-7.

Baldwin, E., A. Plotto, J. Manthey, G. McCollum, J. Bai, M. Irey, R. Cameron, and G. Luzio. 2010. Effect of Liberibacter infection 
(Huanglongbing disease) of citrus on orange fruit physiology and fruit/fruit juice quality: Chemical and physical analyses. J. Agr. Food Chem. 58:1247-1262.

Baldwin, E.A., K. Goodner, and A. Plotto. 2008. Interaction of volatiles, sugars, and acids on perception of tomato aroma and flavor descriptors. J. Food Sci. 73:S294-S307.

Barkley, N., M. Roose, R. Krueger, and C. Federici. 2006. Assessing genetic diversity and population structure in a citrus germplasm collection utilizing simple sequence repeat markers (SSRs). Theor. Appl. Genet. 112:1519-1531.

Barrett, H. and A. Rhodes. 1976. A numerical taxonomic study of affinity relationships in cultivated Citrus and its close relatives. Syst. Bot. 1:105-136.

Dugo, G., A. Cotroneo, I. Bonaccorsi, and A. Trozzi. 2011. Composition of the volatile fraction of Citrus peel oils, p. 1-161. In: G. Dugo and L. Mondello (eds.). Citrus oils. Composition, advanced analytical techniques, contaminants, and biological activity. CRC Press, Boca Raton, FL.

Federici, C., D. Fang, R. Scora, and M. Roose. 1998. Phylogenetic relationships within the genus Citrus (Rutaceae) and related genera as revealed by RFLP and RAPD analysis. Theor. Appl. Genet. 96:812-822.

Florida Department of State. 1995. 20-13.011 Ambersweet: Classification and standards - Florida administrative code \& Florida administrative register; effective 22 Aug. 1995. 23 Jan. 2016. <https://www. flrules.org/gateway/RuleNo.asp?id=20-13.011>.

Florida Senate. 2011. The 2011 Florida statutes: Chapter 601 - Florida citrus code. 23 Jan. 2016. <https://www.flsenate.gov/Laws/Statutes/ 2011/Chapter601>.

Frank, R.A. and J. Byram. 1988. Taste-smell interactions are tastant and odorant dependent. Chem. Senses 13:445-455.

Hearn, C.J. 1989. Yield and fruit quality of 'Ambersweet' orange hybrid on different rootstocks. Proc. Florida State Hort. Soc. 102:75-78.

Högnadóttir, Á. and R.L. Rouseff. 2003. Identification of aroma active compounds in orange essence oil using gas chromatography-olfactometry and gas chromatography-mass spectrometry. J. Chromatography 998:201-211.

Kondjoyan, N. and J.-L. Berdagué. 1996. A compilation of relative retention indices for the analysis of aromatic compounds. Edition du Laboratoire Flaveur, Saint-Genes Champanelle, France.

Li, W., J.S. Hartung, and L. Levy. 2006. Quantitative real-time PCR for detection and identification of Candidatus Liberibacter species associated with citrus huanglongbing. J. Microbiol. Methods 66:104-115.

Lota, M.L., D. de Rocca Serra, F. Tomi, and J. Casanova. 2001. Chemical variability of peel and leaf essential oils of 15 species of mandarins. Biochem. Syst. Ecol. 29:77-104.

Matthews, R.F. 1994. Frozen concentrated orange juice from Florida oranges. Univ. Florida, Inst. Food Agr. Sci. Ext., Gainnsville, FL.

Miyazaki, T., A. Plotto, E.A. Baldwin, J.I. Reyes-De-Corcuera, and F.G. Gmitter, Jr. 2012. Aroma characterization of tangerine hybrids by gas-chromatography-olfactometry and sensory evaluation. J. Sci. Food Agr. 92:727-735.

Moshonas, M.G. and P.E. Shaw. 1997. Quantitation of volatile constituents in mandarin juices and its use for comparison with orange juices by multivariate analysis. J. Agr. Food Chem. 45:3968-3972.

Moshonas, M.G., P.E. Shaw, and R.D. Carter. 1991. Ambersweet orange hybrid: Compositional evidence for variety classification. J. Agr. Food Chem. 39:1416-1421.

Nicolosi, E., Z. Deng, A. Gentile, S. La Malfa, G. Continella, and E. Tribulato. 2000. Citrus phylogeny and genetic origin of important species as investigated by molecular markers. Theor. Appl. Genet. 100:1155-1166.

Perez-Cacho, P.R. and R.L. Rouseff. 2008. Fresh squeezed orange juice odor: A review. Crit. Rev. Food Sci. Nutr. 48:681-695.

Perez-Cacho, P.R. and R. Rouseff. 2008a. Processing and storage effects on orange juice aroma: A review. J. Agr. Food Chem. 56:9785-9796.

Pérez-López, A.J. and Á.A. Carbonell-Barrachina. 2006. Volatile odour components and sensory quality of fresh and processed mandarin juices. J. Sci. Food Agr. 86:2404-2411.

Plotto, A., C.A. Margaría, K.L. Goodner, and E.A. Baldwin. 2008. Odour and flavour thresholds for key aroma components in an orange juice matrix: Esters and miscellaneous compounds. Flavour Fragrance J. 23:398-406.

Plotto, A., C.A. Margaría, K.L. Goodner, R. Goodrich, and E.A. Baldwin. 2004. Odour and flavour thresholds for key aroma components in an orange juice matrix: Terpenes and aldehydes. Flavour Fragrance J. 19:491-498.

Ritenour, M.A. 2014. Orange. In: K. Gross, C.Y. Wang, and M. Saltveit (eds.). The commercial storage of fruits, vegetables, and florist and nursery stocks. 23 Jan. 2016. <http://www.ba.ars.usda. gov/hb66/orange.pdf>.

Shaw, P.E. 1991. Fruit II, p. 305-327. In: H. Maarse (ed.). Volatile compounds in foods and beverages. Marcel Dekker, New York, NY.

Stover, E. and G. McCollum. 2011. Incidence and severity of huanglongbing and Candidatus Liberibacter asiaticus titer among fieldinfected citrus cultivars. HortScience 46:1344-1348.

Swingle, W. and P. Reece. 1967. The botany of Citrus and its wild relatives, p. 190-430. In: W. Reuther, H.J. Webber, and L.D. Batchelor (eds.). The citrus industry. Vol. 1. Univ. California Press, Berkeley, CA.

Tandon, K., E. Baldwin, and R. Shewfelt. 2000. Aroma perception of individual volatile compounds in fresh tomatoes (Lycopersicon esculentum Mill.) as affected by the medium of evaluation. Postharvest Biol. Technol. 20:261-268.

Velasco, R. and C. Licciardello. 2014. A genealogy of the Citrus family. Nat. Biotechnol. 32:640-642.

Wu, G.A., S. Prochnik, J. Jenkins, J. Salse, U. Hellsten, F. Murat, X. Perrier, M. Ruiz, S. Scalabrin, J. Terol, M.A. Takita, K. Labadie, J. Poulain, K. Jabbari, F. Cattonaro, C. Del Fabbro, S. Pinosio, A. Zuccolo, J. Chapman, J. Grimwood, F.R. Tadeo, L.H. Estornell, J.V. Muñoz-Sanoz, V. Ibanez, A. Herrero-Ortega, P. Aleza, J. PérezPérez, D. Ramón, D. Brunel, F. Luro, C. Chen, W.G. Farmerie, B. Desany, C. Kodira, M. Mohiuddin, T. Harkins, K. Fredrikson, P. Burns, A. Lomsadze, M. Borodovsky, G. Reforgiato, J. FreitasAstúa, F. Quetier, L. Navarro, M. Roose, P. Wincker, J. Schmutz, M. Morgante, M.A. Machado, M. Talon, O. Jaillon, P. Ollitrault, F. Gmitter, and D. Rokhsar. 2014. Sequencing of diverse mandarin, pummelo and orange genomes reveals complex history of admixture during citrus domestication. Nat. Biotechnol. 32:656-663.

Xu, Q., L.-L. Chen, X. Ruan, D. Chen, A. Zhu, C. Chen, D. Bertrand, W.-B. Jiao, B.-H. Hao, and M.P. Lyon. 2013. The draft genome of sweet orange (Citrus sinensis). Nat. Genet. 45:59-66.

$\mathrm{Yu}$, Q., A. Plotto, E.A. Baldwin, J. Bai, M. Huang, Y. Yu, H.S. Dhaliwal, and F.G. Gmitter. 2015. Proteomic and metabolomic analyses provide insight into production of volatile and non-volatile flavor components in mandarin hybrid fruit. BMC Plant Biol. 15:76.

Zhao, W., E.A. Baldwin, J. Bai, A. Plotto, and M.S. Irey. 2015. Method for assessing juice/cider quality and/or safety. U.S. Patent Application US20150093755 A1 (Application No. US14/499,508), U.S. Patent Trademark Office, Washington, DC. 